\title{
Genetic association analysis of the IGFBP7, ADAMTS3, and IL8 genes as the potential osteoarthritis susceptibility that maps to chromosome $4 \mathrm{q}$
}

\author{
C Kawahara, T Forster, K Chapman, A Carr, J Loughlin
}

Ann Rheum Dis 2005;64:474-476. doi: 10.1136/ard.2004.027342

Objectives: To determine by genetic association analysis whether the $4 q$ functional candidate genes IGFBP7, ADAMTS3, and IL8 might encode for susceptibility to osteoarthritis (OA).

Methods: Expression of IGFBP7, ADAMTS3, and IL8 in adult OA articular cartilage chondrocytes was demonstrated by reverse transcription-polymerase chain reaction. The genes were screened for common polymorphic DNA variants by direct sequencing of exons, intron-exon boundaries, and the $5^{\prime}$ and $3^{\prime}$ untranslated regions. The variants were genotyped in the female probands from the 146 families which each contained two or more sisters who had undergone total hip replacement (THR) and in 375 female controls matched for age. Variants showing evidence for association were subsequently genotyped in 244 female-THR patients with $\mathrm{OA}$. Allele frequencies between the probands (or patients) and the controls were compared by $\chi^{2}$ analysis.

Results: Fourteen common variants were identified in the three genes. An ADAMTS3 single nucleotide polymorphism was associated in the probands $(p=0.015)$ and an ADAMTS3 insertion/deletion approached significance $(p=0.059)$. However, neither variant was associated in the additional 244 patients with hip OA, with $p$ values of 0.12 and 0.19 , respectively.

Conclusions: The analysis implies that the chromosome $4 \mathrm{q}$ female hip OA susceptibility is not coded for by polymorphism within the functional candidates IGFBP7, ADAMTS3, or IL8.

E pidemiological studies have demonstrated that primary osteoarthritis (OA) has a major genetic component. ${ }^{12}$ A genome wide linkage scan conducted by our group disclosed suggestive linkage to six loci in a cohort of sibling pairs with OA ascertained by joint replacement of the hip or the knee. ${ }^{3}$ Stratification by sex and the replaced joint showed that most of the loci were particularly relevant to hip OA in women. Finer linkage mapping of our chromosome 4 linkage generated a maximum multipoint LOD score of 3.1 at 4q13.1q13.2 in 146 families, each with two or women concordant for primary OA ascertained by total hip replacement (THR). ${ }^{4}$

Using public databases, we searched the chromosome $4 \mathrm{q}$ linkage interval for plausible functional candidate genes. These were selected based upon a reported or suspected role in skeletal joint tissue biology. Three candidates were identified: the IGFBP7, ADAMTS3, and IL8 genes. These genes were scanned for common polymorphic DNA variants, which were then genotyped in the probands from our 146 female-THR families and in a cohort of 375 female controls matched for age, and tested for association with OA.

\section{PATIENTS AND METHODS}

Patients for association analysis

Full clinical details of the 146 female-THR families have been published previously. ${ }^{4}$ Association was also tested in a second cohort comprising 244 female patients with hip OA. The probands and cases were ascertained through the Nuffield Orthopaedic Centre and had undergone total joint replacement of the hip only (mono- or bilateral) for primary OA. The primary status was supported by clinical, radiological, operative, and histological findings and we excluded any secondary forms of the disease or non-OA cases. The 375 female controls were from the general population. All patients and controls were aged 55 or over and were of UK Caucasian origin. Ethical approval for the study was obtained from the Oxfordshire Clinical Research Ethics Committee and informed consent was obtained from all subjects.

\section{Candidate genes}

We were conscious of the fact that the chromosome $4 \mathrm{q}$ susceptibility gene could be positioned at some distance from the point of maximum linkage. ${ }^{5}$ We therefore searched a broad region of $4 \mathrm{q}$ for candidates, between markers D4S2971 $(4 \mathrm{q} 12,53.6 \mathrm{Mb})$ and D4S3042 (4q21.1, 77.3 Mb). We searched the Ensembl (http://www.ensembl.org/, accessed 28 December 2004) and UCSC (http://genome.ucsc.edu/, accessed 28 December 2004) genome browsers. Three candidates were identified and chosen for further investigation (table 1).

\section{Reverse transcription-polymerase chain reaction (RT-} PCR)

Articular cartilage biopsy specimens were collected from patients who had undergone joint replacement for OA. The nucleic acid was then extracted as described previously. ${ }^{6}$ cDNA was synthesised using random hexamers and served as the template for PCR using primers located in separate exons.

\section{DNA variant detection and genotyping}

The exons, the intron-exon boundaries, and the $5^{\prime}$ and $3^{\prime}$ untranslated regions of IGFBP7 (5 exons), ADAMTS3 (22 exons), and IL8 (4 exons) were screened for common DNA variants (rare allele frequency $>0.05$ ) by the direct sequencing of 48 female-THR patients. The variants were genotyped by PCR-restriction enzyme analysis. Further details can be obtained from the corresponding author.

Abbreviations: ADAMTS, a disintegrin and metalloproteinase domain with thrombospondin motifs; Cl, confidence interval; IGF, insulin-like growth factor; IGFBP, insulin-like growth factor binding protein; IL, interleukin; indel, insertion/deletion; $\mathrm{OA}$, osteoarthritis; OR, odds ratio; RT-PCR, reverse transcription-polymerase chain reaction; SNP, single nucleotide polymorphism; THR, total hip replacement 
Table 1 Candidate genes

\begin{tabular}{|c|c|c|c|c|}
\hline $\begin{array}{l}\text { HUGO* } \\
\text { gene name }\end{array}$ & $\begin{array}{l}\text { MIM† } \\
\text { number }\end{array}$ & $\begin{array}{l}\text { Cytogenetic } \\
\text { position }\end{array}$ & $\begin{array}{l}\text { Physical } \\
\text { position } \\
\text { (Mb) } \ddagger\end{array}$ & Protein \\
\hline IGFBP7 & 602867 & $4 q 12$ & 57.8 & Insulin-like growth factor binding protein 7 \\
\hline ADAMTS3 & 605011 & $4 q 13.3$ & 73.6 & $\begin{array}{l}\text { A disintegrin and metalloproteinase with thrombospondin } \\
\text { motifs } 3\end{array}$ \\
\hline IL8 & 146930 & $4 q 13.3$ & 75.1 & Interleukin 8 \\
\hline
\end{tabular}

*Human Genome Organisation (http://www.gene.ucl.ac.uk/hugo/, accessed 28 December 2004); †Mendelian Inheritance in Man (http://www.ncbi.nlm.nih.gov/Omim/, accessed 28 December 2004); $\ddagger$ According to the Ensembl genome browser (http://www.ensembl.org/).

\section{Statistical analysis}

Genetic association, and Hardy-Weinberg equilibrium for the distribution of genotypes, was tested by $\chi^{2}$ analysis with Yates's correction. Odds ratios were calculated with 95\% confidence intervals. The pairwise linkage disequilibrium coefficient $\left(r^{2}\right)^{7}$ was calculated using the GOLD program (http://www.sph.umich.edu/csg/abecasis/GOLD/, accessed 28 December 2004). Haplotype frequencies between variants showing evidence of linkage disequilibrium at $r^{2}>0.2$ were estimated using the EH-PLUS program (http://www.iop. kcl.ac.uk/IoP/Departments/PsychMed/GEpiBST/software.stm, accessed 28 December 2004). Haplotype frequency differences were then compared using $\chi^{2}$.

\section{RESULTS}

\section{Expression by OA chondrocytes and DNA variant detection}

RT-PCR showed that the IGFBP7, ADAMTS3, and IL8 genes were expressed by OA articular cartilage chondrocytes (data not shown). Fourteen common DNA variants were identified in the three genes, comprising 12 single nucleotide polymorphisms (SNPs) and two insertion/deletion (indel) polymorphisms (table 2). Only one of the variants was exonic, the ADAMTS3 exon 3 SNP. This is an A to G transition coding for the substitution of the arginine at amino acid residue 138 by a lysine (Arg138Lys). This SNP is a member of the dbSNP database, with reference number rs788908 (http:// www.ncbi.nlm.nih.gov/SNP/, accessed 28 December 2004). The six IL8 SNPs were all previously identified by Hull et al. ${ }^{8}$

\section{Genotyping and association analysis}

Only the ADAMTS3 SNP (-19) showed evidence for association in the 146 female-THR probands, with a $\mathrm{p}$ value of 0.015. The rare allele of this SNP had a raised frequency in the probands $(0.07)$ versus the controls $(0.03)$. The odds ratio (OR) for the minor allele was 2.29 (95\% confidence interval (CI) 1.22 to 4.29). Because this result could represent a false positive we genotyped the SNP in an independent cohort of 244 female-THR cases. We also genotyped these cases for the ADAMTS3 indel, which had approached significance in the female-THR probands, and for the ADAMTS 3 exon 3 SNP, the only exonic variant. None of the three variants was associated in the 244 cases (table 3 ). The minor allele of the $(-19)$ SNP was raised in the cases (0.05) compared with the controls $(0.03)$, a pattern observed for the probands. When the probands and cases were combined and compared with the controls, there was a significant difference for the $(-19)$ SNP. However, the p value of 0.022 and the OR of 1.91 (95\% CI 1.13 to 3.23) were not as significant as those obtained for the probands alone $(p=0.015, O R=2.29)$. Increasing the sample size had reduced the significance of the association.

Of the six ADAMTS3 variants genotyped, three variant combinations had a pairwise $r^{2}$ value $>0.20$ : $(-7) /(-244)$, with an $r^{2}$ of $0.23 ;(-7) /(+316)$, with an $r^{2}$ of 0.60 ; and $(-244) /(+316)$, with an $r^{2}$ of 0.27 . We estimated the frequency of the eight possible haplotypes for these three variants in the 146 female-THR probands and in the 375 female controls (data not shown). There was no significant difference $(\mathrm{p}=0.17)$.

The three IL8 variants that we genotyped are all in strong linkage disequilibrium with each other: $(-251) /(1633)$ have an $r^{2}$ of $0.82 ;(-251) /(2767)$ have an $r^{2}$ of $0.84 ;(1633) /(2767)$ have an $r^{2}$ of 0.93 . When we estimated the frequency of the eight possible IL8 haplotypes we noted that two haplotypes were extremely common and accounted for over $93 \%$ of the chromosomes for this gene (data not shown). Hull et al

Table 2 IGFBP7, ADAMTS3, and IL8 common DNA variants detected by direct sequencing

\begin{tabular}{|c|c|c|c|c|c|c|c|}
\hline \multirow[b]{2}{*}{ Gene } & \multicolumn{4}{|l|}{ SNP } & \multicolumn{3}{|c|}{ Allele frequencytt (allele numbers) and $p$ value } \\
\hline & Location & Position & $\begin{array}{l}\text { Nucleotide } \\
\text { change }\end{array}$ & $\begin{array}{l}\text { Amino acid } \\
\text { substitution }\end{array}$ & Female controls & Female probands & p Value \\
\hline IGFBP7 & Intron 2 & $+4^{*}$ & T/A & & $0.38(279 / 465)$ & $0.41(116 / 168)$ & 0.37 \\
\hline ADAMTS3 & Intron 1 & $-7 \dagger$ & Indel $\left.\right|^{* *}$ & & $0.45(331 / 397)$ & $0.39(108 / 172)$ & 0.059 \\
\hline ADAMTS3 & Intron 2 & $-244 \dagger$ & $\mathrm{A} / \mathrm{T}$ & & $0.31(229 / 511)$ & $0.33(94 / 190)$ & 0.56 \\
\hline ADAMTS3 & Intron 2 & $-128 \dagger$ & $\mathrm{T} / \mathrm{C}$ & & In complete LD $\ddagger \ddagger$ & ariant ADAMTS3 in & $(-244)$ \\
\hline ADAMTS3 & Exon 3 & $+316 \ddagger$ & $A / G$ & Arg138Lys & $0.38(284 / 458)$ & $0.33(97 / 195)$ & 0.16 \\
\hline ADAMTS3 & Intron 12 & $-19 \dagger$ & $\mathrm{A} / \mathrm{C}$ & & $0.03(22 / 712)$ & $0.07(19 / 269)$ & 0.015 \\
\hline ADAMTS3 & Intron 15 & $+66^{*}$ & $C / T$ & & $0.19(140 / 598)$ & $0.18(51 / 239)$ & 0.67 \\
\hline ADAMTS3 & 3' UTR & $+937 \S$ & G/A & & $0.08(63 / 681)$ & $0.10(29 / 259)$ & 0.49 \\
\hline IL8 & Promoter & $-251^{\top}$ & $\mathrm{A} / \mathrm{T}$ & & $0.44(330 / 414)$ & $0.46(131 / 155)$ & 0.73 \\
\hline IL8 & Intron 1 & $396^{\circ}$ & $\mathrm{G} / \mathrm{T}$ & & In complete LD $\ddagger \ddagger$ & ariant IL8 promoter & \\
\hline IL8 & Intron 1 & $781^{\circ}$ & $\mathrm{C} / \mathrm{T}$ & & In complete LD $\ddagger \ddagger$ & ariant IL8 intron 3 I & \\
\hline IL8 & Intron 2 & $1238^{\circ}$ & Indel ${ }^{* *}$ & & Could not be gen & owing to poly $(A)$ & \\
\hline IL8 & Intron 3 & $1633^{\circ}$ & $\mathrm{T} / \mathrm{C}$ & & $0.42(310 / 420)$ & $0.44(125 / 161)$ & 0.78 \\
\hline IL8 & $3^{\prime}$ UTR & 2767 ब & $A / T$ & & $0.40(295 / 437)$ & $0.43(123 / 163)$ & 0.48 \\
\hline
\end{tabular}

*Relative to end of preceding exon; trelative to start of following exon; łrelative to start of exon 3; §relative to last nucleotide of termination codon; 9 relative to the IL8 gene transcriptional start site; ** of a single (A) nucleotide; ††of the allele that is less common in the controls; $¥+$ linkage disequilibrium (complete LD when $r^{2}=1.01$. 
Table 3 Genotyping of the ADAMTS3 SNPs intron $1(-7)$, exon $3(+316)$, and intron $12(-19)$ in an additional cohort of 244 female-THR cases

\begin{tabular}{|c|c|c|c|c|c|c|c|}
\hline \multirow[b]{2}{*}{ ADAMTS3 SNP } & \multicolumn{7}{|c|}{ Allele frequency (allele numbers) and $p$ value } \\
\hline & Female controls & Female probands & p Value & $\begin{array}{l}\text { Additional } \\
\text { female cases }\end{array}$ & p Value & $\begin{array}{l}\text { Probands and } \\
\text { cases combined }\end{array}$ & p Value \\
\hline Intron $1(-7)$ & $0.45(331 / 397)$ & $0.39(108 / 172)$ & 0.059 & $0.50(228 / 232)$ & 0.19 & $0.45(336 / 404)$ & 0.98 \\
\hline Exon $3(+316)$ & $0.38(284 / 458)$ & $0.33(97 / 195)$ & 0.16 & $0.43(201 / 269)$ & 0.14 & $0.39(298 / 464)$ & 0.78 \\
\hline Intron $12(-19)$ & $0.03(22 / 712)$ & $0.07(19 / 269)$ & 0.015 & $0.05(23 / 443)$ & 0.12 & $0.06(42 / 712)$ & 0.022 \\
\hline
\end{tabular}

previously reported this phenomenon in a European population (haplotypes 1 and 12 of that publication). ${ }^{8}$ There was no significant difference in the frequency of the IL8 haplotypes between our OA probands and our controls $(p=0.20)$.

\section{DISCUSSION}

Selecting candidate genes for an association analysis is a subjective venture influenced by current, and probably limited, knowledge of the biological basis of trait variability. As a first step toward identifying the chromosome 4q hip OA susceptibility we investigated three genes that map within the linkage interval, that have a role in skeletal biology, and which are expressed in OA articular cartilage chondrocytes: IGFBP7, ADAMTS3, and IL8.

Insulin-like growth factors (IGFs) maintain the steady state metabolism of proteoglycans in articular cartilage, ${ }^{9}$ and a number of studies have examined the role of the IGFs and the insulin-like growth factor binding proteins (IGFBPs) in OA. Two interesting recent findings are that IGF-I can reverse the interleukin 1 (ILl) mediated destruction of articular cartilage $^{10}$ and that increasing concentrations of IGFBPs 3 and 5 can lead to improvements in the OA joint. ${ }^{11}$ IGFBP7 has not been subjected to the same intensive investigation as other IGFBPs. However, its expression in OA articular cartilage prompted us to investigate the IGFBP7 gene. We detected no common coding variants and only one common intronic variant, which was not associated with OA.

The ADAMTS (a disintegrin and metalloproteinase domain with thrombospondin motifs) metalloproteinase family includes proteinases which mediate cartilage aggrecan degradation as well as procollagen peptidases involved in collagen biosynthesis. ${ }^{12}$ It has been proposed that ADAMTS3 has a role in the biosynthesis of type II procollagen, the principal collagen of articular cartilage. ${ }^{13}$ The ADAMTS3 gene is large, with 22 exons, a transcript length of $5.8 \mathrm{~kb}$ and a gene length of $288 \mathrm{~kb}$. We identified seven common ADAMTS3 variants. The significant $p$ value observed in the 146 probands for the intron 12 SNP was not replicated in the additional 244 cases. It seems likely, therefore, that this initial positive result was a false positive. The genotyping of this SNP in additional cohorts will support or refute this conclusion.

Cytokines have a role in regulating the catabolic/anabolic balance of articular cartilage, and an increase in catabolic activity mediated by ILI $\beta$ or tumour necrosis factor $\alpha$ (TNF $\alpha$ ) can induce an OA phenotype in model systems. ${ }^{14}$ IL8 appears to be a mediator of cartilage catabolic responses. None of the IL8 variant alleles or haplotypes showed any association with OA in our study.

Overall, we did not generate convincing evidence to support our hypothesis that IGFBP7, ADAMTS3, or IL8 encodes for the hip OA susceptibility that we have linkage mapped to chromosome 4q. We cannot, however, exclude these candidates because variants within regulatory elements of the genes that affect gene expression rather than variants that alter amino acid sequence might predispose to OA.

\section{ACKNOWLEDGEMENTS}

This research was supported by the Arthritis Research Campaign and by Research into Aging.

We thank Ms Kim Clipsham who helped to organise the collection of the patient and family samples used in this study. We acknowledge the encouragement of Professor Shoichi Kokubun.

\section{Authors' affiliations}

C Kawahara, T Forster, K Chapman, A Carr, J Loughlin, Institute of Musculoskeletal Sciences, Botnar Research Centre, University of Oxford, UK

Ethical approval for the study was obtained from the Oxfordshire Clinical Research Ethics Committee and informed consent was obtained from all subjects.

The authors declare that they have no competing interests.

Correspondence to: Dr J Loughlin, University of Oxford, Institute of Musculoskeletal Science, Botnar Research Centre, Nuffield Orthopaedic Centre, Oxford, OX3 7LD, UK; john.loughlin@ndcls.ox.ac.uk

Accepted 22 August 2004

\section{REFERENCES}

1 Loughlin J. Genetic epidemiology of primary osteoarthritis. Curr Opin Rheumatol 2001;13:111-16.

2 MacGregor AJ, Spector TD. Twins and the genetic architecture of osteoarthritis. Rheumatology (Oxford) 1999;38:583-90.

3 Loughlin J. Genetics of osteoarthritis and potential for drug development. Curr Opin Pharmacol 2003;3:295-9.

4 Forster T, Chapman K, Marcelline L, Mustafa Z, Southam L, Loughlin J. Finer linkage mapping of primary osteoarthritis susceptibility loci on chromosome 4 and 16. Arthritis Rheum 2004;50:98-102.

5 Roberts SB, MacLean CJ, Neale MC, Eaves U, Kendler KS. Replication of linkage studies of complex traits: an examination of variation in location estimates. Am J Hum Genet 1999;65:876-84.

6 McKenna LA, Gehrsitz A, Söder S, Eger W, Kirchner T, Aigner T. Effective isolation of high-quality total RNA from human adult articular cartilage. Anal Biochem 2000;286:80-5.

7 Ardlie KG, Kruglyak L, Seielstad M. Patterns of linkage disequilibrium in the human genome. Nat Rev Genet 2002;3:299-309.

8 Hull J, Ackerman H, Isles K, Usen S, Pinder M, Thomson A, et al. Unusual haplotypic structure of IL8, a susceptibility locus for a common respiratory virus. Am J Hum Genet 2001;69:413-19.

9 Luyten FP, Hascall VC, Nissley SP, Morales TI, Reddi AH. Insulin-like growth factors maintain steady-state metabolism of proteoglycans in bovine articular cartilage explants. Arch Biochem Biophys 1988;267:416-25.

10 Wang J, Elewaut D, Veys EM, Verbruggen G. Insulin-like growth factor 1induced interleukin-1 receptor II overrides the activity of interleukin-1 and controls the homeostasis of the extracellular matrix of cartilage. Arthritis Rheum 2003;48:1281-91.

11 Clemmons DR, Busby WH, Garmong A, Schultz DR, Howell DS, Altman RD, et al. Inhibition of insulin-like growth factor binding protein 5 proteolysis in articular cartilage and joint fluid results in enhanced concentrations of insulinlike growth factor 1 and is associated with improved osteoarthritis. Arthritis Rhem 2002;46:694-703.

12 Clark IM, Parker AE. Metalloproteinases: their role in arthritis and potential as therapeutic targets. Expert Opin Ther Targets 2003;7:19-34.

13 Fernandes RJ, Hirohata S, Engle JM, Colige A, Cohn DH, Eyre DR, et al. Procollagen 2 amino acid propeptide processing by ADAMTS3. Insights on dermatosparaxis. J Biol Chem 2001 ;276:31502-9.

14 Goldring MB. The role of the chondrocyte in osteoarthritis. Arthritis Rheum 2000;43:1916-26.

15 Pelletier J-P, Martel-Pelletier J, Abramson SB. Osteoarthritis, an inflammatory disease. Arthritis Rhem $2001 ; 44: 1237-47$. 